\title{
MARCO REGULATÓRIO DA EDUCAÇÃO SUPERIOR BRASILEIRA
}

(D) MARIA DO CARMO DE LACERDA PEIXOTO'

(D) JANE CRISTINA DA SILVA PINTO"

I Universidade Federal de Minas Gerais (UFMG), Belo Horizonte-MG, Brasil; mcarmolp@gmail.com

II Universidade de Brasília (UnB), Brasília-DF, Brasil; janecris1511@gmail.com

\section{RESUMO}

Este artigo discute o marco regulatório da regulação, supervisão e avaliação da educação superior, consolidado no Decreto n. 9.235, de 2017. A análise documental revelou que os atos regulatórios e avaliativos foram simplificados, e a atuação do Estado foi flexibilizada, com a ampliação do escopo das iniciativas a cargo das instituições de educação superior. Além disso, parte dos procedimentos previstos foram remetidos à regulamentação posterior, e ações de supervisão receberam maior detalhamento, explicitando-se as fases desses processos e as medidas cautelares a serem aplicadas pelo poder público.

PALAVRAs-chaVe EDUCAÇÃo SUPERIOR • AVALIAÇÃO dA EDUCAÇÃo • REGULAÇÃo • SINAES. 


\section{MARCO REGULATORIO DE LA EDUCACIÓN SUPERIOR BRASILEÑA}

\section{RESUMEN}

En el presente artículo se discute el marco regulatorio para la regulación, supervisión y evaluación de la educación superior, consolidado en el Decreto n. 9.235, del 2017. En este sentido, el análisis documental reveló cómo los actos regulatorios y evaluativos fueron simplificados, y la actuación del Estado fue flexibilizada con la ampliación del alcance de las iniciativas al cargo de las instituciones de educación superior. Además, una parte de los procedimientos previstos fueron remitidos a una posterior reglamentación, y las acciones de supervisión fueron mucho más detalladas en las fases de estos procesos y en las medidas cautelares aplicables por el poder público.

PALABRAS CLAVE ENSEÑANZA SUPERIOR • EVALUACIÓN DE LA EDUCACIÓN • REGULACIÓN • SINAES.

\section{REGULATORY FRAMEWORK OF THE BRAZILIAN HIGHER EDUCATION}

\section{ABSTRACT}

This article discusses the regulatory framework of regulation, supervision, and evaluation of higher education, established in Decree No. 9235 of 2017. The documentary analysis revealed that the regulatory and evaluative acts were simplified and the State's role was made more flexible with the expansion of the scope of initiatives in charge of higher education institutions. Furthermore, part of the foreseen procedures was referred to later regulation, and supervisory actions were more detailed with regard to the steps of these processes and the precautionary measures to be implemented by the public power.

KEYWORDS HIGHER EDUCATION • EDUCATIONAL EVALUATION • REGULATION • SINAES. 


\section{INTRODUÇÃO}

Este artigo é parte da pesquisa em andamento "Nova Gestão Pública e a reconfiguração da avaliação e regulação da educação superior”, com apoio do Conselho Nacional de Desenvolvimento Científico e Tecnológico (CNPq). Tem por objetivo compreender e analisar a reconfiguração da avaliação e da regulação da educação superior na emergência da Nova Gestão Pública em face do novo perfil dos estudantes e de seu desempenho nas avaliações do Exame Nacional de Desempenho de Estudantes (Enade). ${ }^{1}$

A introdução da Nova Gestão Pública (NGP) enfatizou a maior eficiência da administração pública e modificou os modos de regulação social. Na educação superior brasileira, essas mudanças afetaram os processos de regulação e avaliação. Sucessivas mudanças foram sendo introduzidas no ordenamento desses processos, constituindo um conjunto de normas abrangente, no qual ressalta a presença de interesses de diversas ordens visando à administração mais eficiente do sistema e, também, a atender a interesses específicos de diversos segmentos que atuam nessa faixa da educação.

A análise dos atos normativos sobre a educação superior, publicados ao longo de um período, permite compreender a estruturação dos processos de regulação, supervisão e avaliação, assim como tendências evidenciadas. Buscas no portal do Ministério da Educação (MEC) e nas páginas eletrônicas da Secretaria de Regulação e Supervisão da Educação Superior (Seres), do Instituto Nacional de Pesquisas e Estudos Educacionais Anísio Teixeira (Inep), da Imprensa Nacional(IN), do Conselho de Reitores das Universidades Brasileiras (Crub) e da Associação Brasileira de Mantenedoras de Ensino Superior (ABMES) resultaram na identificação de 631 documentos, entre leis, decretos, portarias, portarias normativas, resoluções e instruções normativas, publicados entre 2001 e 2019. Neste artigo, foi feito um recorte dessa documentação, focalizando o marco normativo vigente, estabelecido com a publicação do Decreto n. 9.235, de 15 de dezembro de 2017 (BRASIL, 2017a), que dispõe sobre as funções de regulação, supervisão e avaliação das instituições de educação superior e dos cursos superiores de graduação e de pós-graduação no Sistema Federal de Ensino. ${ }^{2}$

1 Dela participam pesquisadores da Universidade de Brasília (UnB), da Universidade Federal de Minas Gerais (UFMG), da Universidade Estadual de Goiás (UEG), da Universidade Estadual do Maranhão (UEMA) e da Universidade Regional de Blumenau (FURB). A pesquisa constitui um dos eixos do projeto integrado "Políticas, gestão e direito à educação superior: novos modos de regulação e tendências em construção", conduzido por pesquisadores da Rede Universitas/BR.

2 Nos termos do art. 16 da Lei de Diretrizes e Bases da Educação (LDB), o Sistema Federal de Ensino compreende as instituições de educação superior mantidas pela União, as instituições de ensino superior (IES) mantidas pela iniciativa privada e os órgãos federais de educação. O Decreto n. 9.235, de 15 de dezembro de 2017, estabeleceu, no art. $2^{\circ}$, que as IES criadas e mantidas por pessoas jurídicas de direito privado sujeitam-se ao sistema federal de ensino, assim como as IES criadas pelo poder público estadual, distrital ou municipal mantidas por pessoas jurídicas de direito privado e as IES qualificadas como instituições comunitárias. 
O texto está organizado em três seções. Na primeira, são discutidas as articulações entre a Nova Gestão Pública, a avaliação e a regulação da educação superior. Na segunda seção, é abordado um histórico das políticas de regulação e avaliação da educação superior no Brasil, e, na terceira seção, são analisadas as alterações introduzidas pelo marco regulatório em vigor. Considerações sobre o que foi abordado no decorrer do artigo são apresentadas ao final.

\section{NOVA GESTÃO PÚBLICA: REGULAÇÃO E AVALIAÇÃO DA EDUCAÇÃO SUPERIOR}

Nas duas últimas décadas do século XX, a Nova Gestão Pública, associada à globalização da economia e à ideologia neoliberal, ganhou centralidade nas políticas públicas de gestão e administração, pela incorporação e implementação de princípios de racionalidade empresarial e de gestão privada nas instituições e organizações públicas, em busca de maior eficiência e produtividade. Esse fenômeno e seus efeitos sobre a educação superior têm sido objeto de análise de diversos autores.

Verger e Normand (2015) consideram que o desenvolvimento de reformas da NGP desagrega as funções de provedores e usuários, fragmenta os serviços públicos e promove uma gestão baseada em resultados. ${ }^{3}$ Segundo os autores, o fato de a educação deter grande dotação orçamentária e ter grande quantidade de pessoas ocupadas torna o setor especialmente propenso à aplicação das reformas, alterando bastante a concepção de governança das instituições educativas. A adoção da Nova Gestão Pública na educação e a maneira como ela se configura em marcos regulatórios e programas educativos podem apresentar distintos modos de governança e de políticas. Com base em estudos realizados em diversos países, a NGP “[...] es probablemente uno de los modelos de reforma educativa global que refleja más contradicciones y tensiones a la hora de transitar de la teoría a la práctica, o de lo global a lo local" (VERGER; NORMAND, 2015, p. 618). ${ }^{4}$

Nesse sentido, Barroso (2006) identificou três tipos de regulação na educação: transnacional, nacional e microrregulação local. A transnacional é constituída por um conjunto de normas, discursos e instrumentos produzidos em fóruns internacionais na área educacional e que são tomados como impositivos para sua adoção no nível educativo de sistemas nacionais. A regulação nacional é constituída pelo “[...] modo como as autoridades públicas exercem a coordenação, o controle e a influência sobre o sistema educativo” (p. 50), enquanto a microrregulação local resulta

3 Newman e Clarke (2012) discutem o papel do gerencialismo como nova forma de poder no serviço público.

4 Em tradução livre: a NGP "se situa provavelmente entre os modelos de reforma educativa global que mais contradições e tensões apresenta ao transitar da teoria para a prática, ou do global para o local". 
das estratégias, negociações e ações de vários atores, “[...] pelos quais as normas, injunções e constrangimentos da regulação nacional são (re)ajustados localmente, muitas vezes de modo não intencional” (p. 56).

Afonso e Mendes (2018) afirmam que a NGP se tornou um dos pilares estruturantes da agenda global para a educação, tendo alguns de seus princípios se concretizado por meio da redefinição do papel do Estado e de alterações nos procedimentos da administração pública, liberando o mercado do controle do Estado e reduzindo seu tamanho, âmbito e custos. Induziu também mudanças nos modos de regulação social no contexto de internacionalização capitalista.

As alterações produzidas pela NGP resultaram na busca por resultados ou produtos dos sistemas de ensino, substituindo ou complementando a regulação baseada em normas e incentivos. Coletados por meio de avaliações estandardizadas e analisados a posteriori, esses resultados "[...] começaram a ser entendidos no âmbito de uma nova forma de regulação pelo conhecimento ou regulação pós-burocrática" (AFONSO; MENDES, 2018, p. 3-4).

Para Barroso e Carvalho (2011), como a fabricação e a regulação das políticas tendem a ser mais intensivas em conhecimentos, "[...] as lutas políticas são indissociáveis dos conflitos, dos consensos ou das mutações produzidas sobre os conhecimentos em circulação. Mas elas são também inseparáveis da capacidade de expressão e da legitimidade das diversas formas de conhecimento” (p. 21). Assim sendo, “[...] é importante ter em conta que os diversos tipos de conhecimento são, em si mesmos, constitutivos de processos políticos distintos - novos modos de conhecimento associam-se a novas formas de acção pública e de participação na multirregulação das políticas” (p. 21). Essa multirregulação resulta “[...] dos interesses, estratégias e lógicas de acção de diferentes grupos de actores, por meio de processos de confrontação, negociação e recomposição de objetivos e poderes” (BARROSO, 2005, p. 734).

Instrumento essencial ao processo regulatório, a avaliação tem participação na verificação do cumprimento das normas. Por essa razão, ela se torna um dos eixos estruturantes das reformas da administração pública na NGP, com implicações para o campo educacional, em especial para a educação superior, intensificando seu papel como mecanismo de controle das instituições educacionais.

O Estado-avaliador (NEAVE, 1998), caracterizado pela adoção de instrumentos de acompanhamento do desempenho das escolas, visa a orientar as políticas públicas de acordo com as leis do mercado e aplicar mecanismos de controle e responsabilização sobre os resultados dos sistemas educacionais. Segundo Afonso (2013), ao longo do tempo essa forma de Estado conformou distintas etapas, a primeira delas característica das décadas de 1980 e 1990, marcada por políticas de avaliação em larga escala realizadas internamente em um país, com a “[...] introdução de 
mecanismos de accountability baseados em testes estandardizados de alto impacto e em rankings escolares" (p. 272). A segunda etapa, no final dos anos 1990 e início dos anos 2000, refere-se à construção de um sistema de indicadores e de avaliação internacional comparada em larga escala, marcada pela presença de organizações internacionais na criação de políticas nacionais para a educação. Levou à "[...] redução crescente da autonomia relativa do Estado-nação e maior protagonismo de instâncias internacionais e transnacionais” (p. 278).

A terceira etapa, formulada ainda como hipótese com base em alguns indicadores, foi denominada de pós-Estado-avaliador. Caracteriza-se pela ampliação de formas de avaliação comparada entre países, que estabeleceriam pontos de referência para a garantia de qualidade educacional, abrangendo principalmente o ensino superior “[...] e não significa, antes pelo contrário, que a avaliação saia da ordem do dia, mas, antes, que fugirá cada vez mais do âmbito do Estado nacional” (AFONSO, 2013, p. 280). De acordo com Afonso, nessa etapa, os sistemas e as agências de avaliação ampliam a privatização e/ou o incremento de políticas de avaliação, comuns aos blocos regionais como União Europeia e Mercosul. ${ }^{5}$

Diante da complexidade desse contexto, será observado, no caso brasileiro, como tem ocorrido o processo de articulação entre regulação e avaliação na educação superior.

\section{REGULAÇÃO E AVALIAÇÃO NA EDUCAÇÃO SUPERIOR BRASILEIRA}

O processo de articulação entre avaliação e regulação da educação superior foi construído a partir de diferentes e descontinuadas experiências e propostas para a avaliação a partir da década de 1980. A primeira iniciativa de implementação da avaliação da graduação na educação superior brasileira foi o Programa de Avaliação da Reforma Universitária (Paru), inspirado na avaliação da pós-graduação da Capes. Instituído em 1983, com foco na gestão das IES e no processo de produção e disseminação do conhecimento nas universidades, produziu um diagnóstico da universidade e das questões emergenciais a serem transformadas (BELLONI, 2000). Disputas internas e ausência de apoio do MEC levaram a encerrar do programa em 1984, e, mesmo não tendo atingido plenamente os objetivos, “[...] o Paru influenciou direta e indiretamente as questões de avaliação, por força das amplas discussões promovidas e da diversidade de instituições envolvidas" (SOUZA, 2012, p. 90 apud ZANOTTO, 2014, p. 25).

5 No caso brasileiro um possível indicador para essa hipótese é o fato de que, desde o início dos anos 2000, o país integra o Sistema Regional de Acreditação de Cursos Universitários do Mercosul (Arcu-Sul), do qual fazem parte Argentina, Paraguai, Uruguai, Bolívia, Chile e Colômbia. O Arcu-Sul é gerenciado pela Rede de Agências Nacionais de Acreditação (Rana) e oferece, para os sete países da região que firmaram o acordo, garantia pública do nível acadêmico dos cursos avaliados. 
Em 1985, foi instituída a Comissão Nacional para a Reformulação da Educação Superior, visando a oferecer subsídios à formulação de uma nova política para a educação superior brasileira. Foram abordados aspectos relacionados à ampliação da autonomia das universidades, à participação da comunidade acadêmica na gestão, ao controle social da universidade e à implementação de processo de avaliação externa (BRASIL, 1985). Para sistematizar esses subsídios, convocar a comunidade ao debate e preparar as medidas administrativas e legais de reformas necessárias, em 1986, o MEC criou o Grupo Executivo da Reforma da Educação Superior (Geres). O Grupo propôs a implementação do controle social sobre a autonomia universitária, por meio da avaliação do desempenho institucional e da qualidade dos cursos, a ser conduzida pela SESu/MEC por meio de Comissões de Especialistas de Ensino e encaminhados para o Conselho Federal de Educação (CFE) (BRASIL, 1986). Essa iniciativa não prosperou, em face da resistência encontrada na comunidade acadêmica.

A criação da Comissão Nacional de Avaliação das Universidades Brasileiras, em 1993, composta por entidades representativas da universidade e por especialistas, levou à instituição o Programa de Avaliação Institucional das Universidades Brasileiras (Paiub). A Comissão deveria conduzir politicamente o processo de avaliação institucional, sendo o MEC coordenador, articulador e agente financiador desse processo, em parceria com as universidades (BRASIL, 1994). No Paiub, a avaliação institucional deveria ser um processo contínuo de aperfeiçoamento do desempenho acadêmico, ferramenta para o planejamento e gestão, e processo de prestação de contas à sociedade, sendo desenvolvido em três fases: avaliação interna, externa e reavaliação (COMISSÃO NACIONAL DE AVALIAÇÃO, 1993). Entendida como ato político e voluntário da instituição, a avaliação visava à melhoria do projeto acadêmico e social, por meio de um processo de autoconhecimento e numa perspectiva formativa e emancipatória (BARREYRO; ROTHEN, 2008). A partir de 1995, teve início a implementação da avaliação da educação superior em larga escala, deixando o Paiub de ser financiado pelo MEC. Alguns de seus mecanismos foram mantidos de acordo com as disponibilidades das IES.

A avaliação em larga escala teve início com a aplicação do Exame Nacional de Cursos (ENC), criado pela Lei n. 9.131 (BRASIL, 1995), destinado a concluintes de cursos de graduação. A ênfase nos resultados e na produtividade, como base para controle e regulação pelo Estado por meio da avaliação das condições de ensino e das condições de oferta, mudou o paradigma vigente e marcou o início do processo de articulação entre avaliação e regulação.

Esse processo avançaria com a instituição do Plano Nacional de Educação (PNE) 2001-2010, pela Lei n. 10.172 de 2001 (BRASIL, 2001b), que trouxe, entre os objetivos e metas, quatro itens relacionados à avaliação e regulação da educação. No item 
6, propõe a criação de um sistema nacional de avaliação interna e externa, englobando setores público e privado, destinado a promover a melhoria da qualidade do ensino, da pesquisa, da extensão e da gestão acadêmica, enquanto que, no item 7, propõe estabelecer programas de fomento para a constituição de sistemas próprios de avaliação institucional e de cursos, e, no item 8, estende diferentes prerrogativas de autonomia às instituições não universitárias públicas e privadas. A articulação entre avaliação e regulação é formalizada no item 9, que estabelece o recredenciamento de IES e o reconhecimento de cursos com base na avaliação.

Atendendo ao previsto no PNE e na Lei n. 9.394 (BRASIL, 1996), que estabeleceu as Diretrizes e Bases da Educação Nacional (LDB), foi aprovada a Lei n. 10.861 (BRASIL, 2004), que instituiu o Sistema Nacional de Avaliação da Educação Superior (Sinaes). De acordo com o $\S 1^{\circ}$ do art. $1^{\circ}$, o Sinaes tem por finalidades a melhoria da qualidade da educação superior; a orientação e expansão da oferta; o aumento permanente da eficácia institucional e efetividade acadêmica e social; o aprofundamento dos compromissos e responsabilidades sociais das instituições de educação superior, por meio da valorização da sua missão pública, da promoção dos valores democráticos, do respeito à diferença e à diversidade, da afirmação da autonomia e identidade institucional.

No Sinaes, as duas dimensões são claramente articuladas. A avaliação tem natureza formativa, com foco na qualidade, e a regulação tem por referencial os resultados obtidos nos processos avaliativos para autorização, credenciamento, recredenciamento e outros atos necessários ao funcionamento de cursos e de instituições de ensino.

O PNE 2014-2024, instituído pela Lei n. 13.005 (BRASIL, 2014), reforça o papel da avaliação para a melhoria da qualidade da educação superior, vinculada aos processos de regulação com ênfase na supervisão e no controle externo das instituições. Nas estratégias das metas de número 12 e 13, essa formalização tem continuidade. $\mathrm{Na}$ meta 12, é proposta a reestruturação dos procedimentos adotados na área de avaliação, regulação e supervisão, com ênfase na melhoria de prazos e qualidade da decisão dos atos regulatórios; e, na meta 13, é ressaltado o aperfeiçoamento do Sinaes por meio do fortalecimento das ações de avaliação, regulação e supervisão; a ampliação da cobertura do Enade; e a indução de processo contínuo de autoavaliação das IES, fortalecendo a participação das comissões próprias de avaliação.

O marco normativo em vigor na educação superior brasileira, estabelecido com a edição do Decreto n. 9.235 (BRASIL, 2017a), é o tema da próxima seção. Serão indicadas suas características, principais alterações promovidas e a relação entre avaliação e regulação da educação superior a partir de sua vigência. 


\section{O MARCO NORMATIVO EM VIGOR}

Do início deste século até o ano de 2006, a organização e a avaliação da educação superior brasileira eram regulamentadas pelo Decreto n. 3.860 (BRASIL, 2001a), focalizando a organização acadêmica das IES e a criação e avaliação de cursos e instituições. A publicação do Decreto n. 5.773 (BRASIL, 2006) deu início ao processo de sistematização e articulação da regulação e da avaliação conforme consta da lei do Sinaes, dispondo sobre o exercício das funções de regulação, supervisão e avaliação das IES e dos cursos superiores de graduação e sequenciais no Sistema Federal de Ensino (SFE).

Em 2007, foi publicada a Portaria Normativa n. 40, que instituiu o e-MEC, sistema eletrônico de fluxo de trabalho e gerenciamento de informações relativas aos processos de regulação da educação superior no SFE. A portaria detalhou os processos autorizativos de funcionamento na modalidade presencial e a distância, o processo de avaliação no Inep e as comissões de avaliadores, a regulação no Conselho Nacional de Educação (CNE) e o ciclo avaliativo (BRASIL, 2007).

Em 2010, essa portaria foi republicada e consolidada, com o objetivo de "[...] simplificar, racionalizar e abreviar o trâmite dos processos" relacionados no Decreto n. 5.773 (BRASIL, 2006). A portaria foi acrescida de novos itens, entre eles a possibilidade de dispensa da avaliação in loco para a autorização de cursos presenciais conforme Conceito Institucional (CI) e Índice Geral de Cursos (IGC) da IES; ingresso e exclusão de avaliadores e instrumentos de avaliação; procedimentos relativos ao Enade; possibilidade de prorrogação do recredenciamento ou da renovação de reconhecimento com Conceito Preliminar de Curso (CPC) ou IGC satisfatórios, ato de autorização válido e ausência de medida de supervisão. A portaria instituiu também o cadastro eletrônico e-MEC como base de dados oficial e única de informações relativas às IES e cursos e o Cadastro Nacional de Docentes, de responsabilidade das instituições, e normatizou a coleta de informações sobre estudantes no Censo da Educação Superior.

O grau progressivo de detalhamento do conteúdo desses documentos indica a ampliação de abrangência que foi sendo impressa aos atos de regulação e avaliação. Ao mesmo tempo, essa maior abrangência resulta da ampliação da dimensão e complexidade da educação superior brasileira, em consequência da expansão do sistema e da diversidade e amplitude dos processos avaliativos.

Em 2011, foi criada a Seres, ${ }^{6}$ que assumiu todas as atividades de regulação e supervisão da educação superior, antes dispersas entre outras secretarias do Ministério. ${ }^{7}$

7 A Secretaria de Ensino Superior (SESu), a Secretaria de Educação Profissional e Tecnológica (Setec) e a Secretaria de Educação a Distância (Seed). 
A Seres passa a ser a principal responsável pela formulação de políticas para regulação e supervisão de cursos e IES públicas e privadas do SFE, ao mesmo tempo em que a regulação da educação superior se consolida como atividade integrante do organograma do MEC.

Em 2017, foi publicado o Decreto n. 9.235, que dispõe sobre o exercício das funções de regulação, supervisão e avaliação das IES e dos cursos superiores e de pós-graduação no SFE (BRASIL, 2017). Tanto o Decreto n. 5.773 quanto a Portaria n. 40 foram revogados, sendo atualizado o Decreto com a exclusão da referência aos cursos sequenciais ${ }^{8}$ e incorporados os cursos de pós-graduação lato sensu aos processos de regulação, supervisão e avaliação, tendo sido incluídos aspectos da Portaria n. 40 concernentes à flexibilização e à simplificação dos atos regulatórios e de procedimentos avaliativos. Especificidades relacionadas à regulação, supervisão e avaliação da educação superior trazidas pelo Decreto serão discutidas a seguir.

\section{Processos de regulação e avaliação: finalidades e competências}

O Decreto n. 9.235 (BRASIL, 2017a) explicitou as finalidades dos processos regulatórios. No art. $1^{\circ}$, foi definido um conjunto de finalidades para a regulação, tendo como seus objetivos promover a igualdade de condições de acesso, garantir o padrão de qualidade das IES e cursos, estimular o pluralismo de ideias e concepções pedagógicas e a coexistência de IES públicas e privadas de ensino, ratificando, nesse último caso, o disposto no inciso III do art. 206 da Constituição Federal. Nessa definição de objetivos, observa-se a ampla área abarcada pelos processos de regulação da educação superior, chamando a atenção, no entanto, a inadequação do primeiro deles enquanto finalidade da regulação. Embora seja uma questão de redação, promover a igualdade de condições de acesso tem mais a ver com as finalidades da educação do que com as da regulação.

Na supervisão, o Decreto explicita como finalidade a promoção de ações preventivas ou corretivas no cumprimento das normas gerais da educação superior, de forma a zelar pela regularidade e qualidade da oferta de cursos. A avaliação, conforme consta do $\S 3^{\circ}$ do art. $1^{\circ}$, deve ser realizada com caráter formativo, em conformidade com a concepção presente na lei de criação do Sinaes.

Quanto às competências dos órgãos, o Decreto vigente trouxe alterações no que se refere àqueles envolvidos nos processos de avaliação, de forma a ampliar as atribuições do Inep e restringir o papel da Comissão Nacional de Avaliação da Educação

8 A Resolução CES/CNE n. 1, de 22 de maio de 2017 (BRASIL, 2017b), que dispõe sobre os cursos sequenciais, determinou, no art. $3^{\circ}$, que os cursos sequenciais de formação específica regularmente oferecidos pelas Instituições de Educação Superior teriam a oferta encerrada em definitivo, no prazo máximo de dois anos, contados a partir da sua publicação. 
Superior (Conaes). De acordo com o Decreto anterior, cabia ao Inep a operacionalização do Sinaes, por meio da realização de visitas para avaliação in loco; avaliação de instituições, cursos e desempenho dos estudantes; elaboração dos instrumentos de avaliação conforme diretrizes da Conaes; constituição e manutenção de banco público de avaliadores. Na Portaria n. 40, era mencionada a atividade de avaliação como de responsabilidade do Inep.

No art. $7^{\circ}$ do Decreto n. 9.235 (BRASIL, 2017a), o Inep é entendido como responsável por conceber, planejar, coordenar e operacionalizar a avaliação das IES, cursos e escolas de governo e do Enade, além de conceber, planejar, coordenar, operacionalizar, avaliar e atualizar os indicadores dos instrumentos da avaliação externa in loco, o que lhe confere protagonismo da avaliação em relação à Conaes. Nos incisos III e IV, a elaboração dos instrumentos e dos indicadores se fará em consonância com as diretrizes propostas pela Seres. Essa vinculação à Seres das diretrizes para elaboração dos instrumentos da avaliação externa amplia as finalidades da regulação subordinando parcialmente a avaliação à regulação.

Quanto à Conaes, o Decreto n. 9.235 (BRASIL, 2017a) reduz suas atribuições, em especial pela omissão quanto à responsabilidade pela coordenação e supervisão do Sinaes e ao estabelecimento de diretrizes para os instrumentos de avaliação e para constituição e manutenção do banco de avaliadores, que constavam dos incisos I, II e III do Decreto anterior. Um olhar comparativo entre a Lei n. 10.861 (BRASIL, 2004) e os dois decretos, no entanto, permite perceber que, no caso da Conaes, o art. $8^{\circ}$ do Decreto n. 9.235/2017 restaurou competências já contidas no art. $6^{\circ}$ da referida Lei.

Deve ser observado ainda que o CNE, no art. $1^{\circ}$ da resolução CNE/CES n. 1 de 2019 (BRASIL, 2019a), delegou competência ao Secretário de Regulação e Supervisão da Educação Superior para a prática de atos de regulação compreendidos nos arts. 24, 27 e 32, $\S 1^{\circ}$ do Decreto n. 9.235. Esses artigos dizem respeito aos atos de credenciamento provisório, de concessão da prerrogativa para faculdades com CI máximo registrarem os diplomas por elas expedidos e da extensão de prerrogativas de autonomia para campus fora de sede de universidades pertencentes ao SFE. Ao delegar à Seres o exercício de atribuições da Câmara de Educação Superior, o CNE amplia as competências dessa secretaria no que concerne à regulação.

As alterações produzidas pelo Decreto n. 9.235 sobre a regulação, a supervisão e a avaliação da educação superior serão discutidas a seguir.

\section{A regulação}

No $\S 4^{\circ}$ do art. 10 do Decreto n. 9.235, é anunciado que os processos relativos aos atos autorizativos poderão ser simplificados de acordo com os resultados da avaliação, em contradição com o que previa a Portaria n. 40 e do que foi estabelecido na Lei do Sinaes. Essa simplificação é explicitada com a possibilidade da dispensa de 
avaliação externa nos processos de autorização, caso a IES tenha CI igual ou maior que 3 (três), inexista processo de supervisão e ofereça curso na mesma área de conhecimento, como consta do art. 42.

Além disso, consta do art. 49 que a avaliação in loco poderá ser realizada por uma comissão única de avaliadores, quando se tratar de grupos de cursos, de cursos do mesmo eixo tecnológico ou da mesma área do conhecimento. Esse dispositivo modifica o que previa o $\S 1^{\circ}$ do art. 14 da Portaria n. 40 (BRASIL, 2010), a qual prescrevia que as comissões deveriam ser compostas por dois avaliadores para cursos e de três para IES. Essas prerrogativas de dispensa de visita in loco já estavam previstas na Portaria. A operacionalização da avaliação nos moldes descritos foi remetida para regulamentação posterior pelo MEC, tendo essa dispensa sido regulamentada no caso de processos de autorização de cursos, pela Portaria Normativa n. 20 de 21 de dezembro de 2017, republicada em 2018.

Quanto ao credenciamento de IES, de acordo com o art. 19 do Decreto n. 9.235, o pedido pode ser feito tanto na modalidade presencial como a distância, ou em ambas as modalidades, tramitando em conjunto com o pedido de autorização de até cinco cursos de graduação. No $\S 3^{\circ}$ do mesmo artigo, é prescrito que, embora as licenciaturas possam constar do conjunto de cursos oferecidos pela IES, elas não são incluídas no grupo de cinco cursos do pedido de credenciamento. Na prática, isso possibilita que a IES solicite o credenciamento com cinco bacharelados e/ou cursos tecnológicos e um número ilimitado de licenciaturas, possibilitando o início de funcionamento da IES ancorado por um número superior ao do conjunto de cinco previsto no $\S 2^{\circ}$.

A simplificação de processos do Decreto n. 9.235 não ficou restrita aos atos de autorização e de reconhecimento de cursos. No art. 24, o decreto introduz o credenciamento prévio, novo tipo de ato destinado à abertura de instituições de educação superior e campus fora de sede de universidades e de centros universitários vinculados, cujas mantenedoras tenham todas as mantidas já recredenciadas, com CI maior ou igual a 4, e sem penalidades em processo de supervisão. Esse credenciamento prévio também deve ser acompanhado do pedido de autorização de até cinco cursos. O credenciamento definitivo se dá após a avaliação externa pelo Inep, que identificará a suficiência das condições da IES. Caso contrário, o processo será indeferido, ficando a mantenedora impedida de protocolar novos processos de credenciamento pelo prazo de dois anos.

O Decreto n. 9.235 também estabelece, no art. 27, que as faculdades poderão dispor da atribuição de registrar seus próprios diplomas de graduação, nos termos de seu ato de recredenciamento e conforme regulamento a ser editado pelo MEC. Essa alteração se aplica a faculdades com CI máximo nas duas últimas avaliações que ofertem pelo menos um curso de pós-graduação stricto sensu e que não tenham sido 
penalizadas em processo de supervisão. Embora o art. 48 da Lei n. 9.394 (BRASIL, 1996) tenha restringido o registro de diplomas a universidades, no $\S 2^{\circ}$ do art. 54 dessa lei, é feita ressalva de que "[...] atribuições de autonomia universitária poderão ser estendidas a instituições que comprovem alta qualificação para o ensino ou para a pesquisa, com base em avaliação realizada pelo Poder Público”.

O Parecer CNE/CES n. 398 (BRASIL, 2019b), aguardando homologação, regulamenta o mencionado $\S 2^{\circ}$ do art. 54 , definindo que a alta qualificação acadêmica para o ensino ou a pesquisa abrange aquelas instituições que tenham obtido CI igual a 5 em dois últimos períodos avaliativos consecutivos. No Parecer, é considerado que as IES assim classificadas poderão usufruir das atribuições da autonomia universitária para a criação de cursos de graduação e demais programas de educação superior com a dispensa de avaliação in loco; fixar currículos e vagas; elaborar e reformar estatutos e regimentos; e conferir graus, diplomas e outros títulos. Essas prerrogativas ficarão suspensas até o período avaliativo seguinte, caso a IES não mantenha o conceito 5 por duas avaliações trienais consecutivas.

\section{A supervisão}

No Decreto em vigor, a supervisão tem seus procedimentos detalhados de forma mais extensa em comparação com o que constava do Decreto n. 5.773 (BRASIL, 2006). O processo de supervisão tem suas fases especificadas nos arts. 62 a 78, o que corresponde a mais que o dobro de artigos sobre supervisão do decreto anterior. $\mathrm{O} \S$ $3^{\circ}$ do art. 62 prescreve que as ações de supervisão poderão ser exercidas em articulação com os conselhos de profissões regulamentadas.

O processo de supervisão poderá ser constituído por três fases: procedimento preparatório, procedimento saneador e procedimento sancionador, e, no art. 63, são descritas nove medidas cautelares passíveis de aplicação, "[...] em caso de risco iminente ou ameaça de interesse público e ao interesse dos estudantes, motivadamente, sem a prévia manifestação do interessado" (BRASIL, 2017a), enquanto no Decreto n. 5.773 elas eram apenas quatro e a serem aplicadas de forma motivada após recebida a defesa da IES. No art. 72, o Decreto n. 9.235 detalha um conjunto de irregularidades administrativas, como a oferta de educação superior sem ato autorizativo ou em desconformidade com os atos autorizativos da IES, terceirização da oferta de educação superior, passíveis de penalidades.

\section{A avaliação}

A Portaria Normativa n. 40/2010 teve grande parte dos seus itens contemplados nos artigos referentes à avaliação do Decreto n. 9.235, com redução do nível de detalhamento, remetido a regulamentações posteriores. A tramitação do processo na fase de avaliação externa in loco, regulamentada pelos art. 81 a 85 do Decreto, foi 
estruturada com base na Portaria, que detalhava o processo de seleção dos avaliadores e a participação da Comissão Técnica de Acompanhamento e Avaliação (CTAA) no processo de avaliação.

O Decreto n. 9.235 aborda os aspectos que deverão ser considerados pelos avaliadores na avaliação externa e atribui ao Inep a seleção, capacitação, recapacitação e elaboração dos critérios de permanência dos avaliadores no banco. Assim sendo, a tramitação do processo de avaliação externa passa a depender de regulamentação posterior pelo Inep. A regulamentação do Enade, constante dos arts. 86, 87 e 88, não constava do Decreto n. 5.773 e replica de forma resumida as especificações que constavam da Portaria n. 40.

Os indicadores da qualidade da educação superior têm uma configuração diferente a ser considerada. Do art. 33-B da Portaria n. 40, constava, como indicador de cursos, o Conceito Preliminar de Curso (CPC) e, como indicador das instituições de ensino superior, o Índice Geral de Cursos (IGC), ambos instituídos em 2008, sendo indicador do desempenho dos estudantes o resultado obtido no Enade. Em 2016, o MEC publicou a Portaria Normativa n. 8 (BRASIL, 2016), que instituiu o Grupo de Trabalho de Avaliação do Desempenho da Educação Superior (GTAES), com o objetivo de trabalhar na elaboração, definição de metodologia dos indicadores de qualidade da educação superior e sua implementação. De acordo com Pereira, Araújo e Machado-Taylor (2020, p. 15), teriam sido criados seis novos indicadores e reformulados outros dois, totalizando oito, ainda aguardando publicação. O art. 89 do Decreto n. 9.235 menciona indicadores, mas não explicita quais seriam eles. No parágrafo único desse artigo, está dito que a definição, a metodologia de cálculo, o prazo e a forma de divulgação dos indicadores devem ser remetidos a regulamento a ser editado pelo Inep após aprovação pela Conaes.

Pode-se concluir que o quadro normativo atual tem por características a aplicação de medidas que visam à simplificação dos atos e dos procedimentos regulatórios e avaliativos, além da flexibilização da ação do Estado por meio da ampliação do escopo de iniciativas que podem ser tomadas pelas IES, independentemente da regulação do MEC. Por outro lado, as ações de supervisão ganham relevo nas normas vigentes, com a definição das fases, bem como das medidas cautelares que podem ser determinadas pelo poder público. Quanto à avaliação, as principais alterações dizem respeito à previsão de uma comissão única de avaliação externa e à reconfiguração das atribuições do Inep e da Conaes.

\section{CONSIDERAÇÕES FINAIS}

Neste artigo foi analisado o marco regulatório da educação superior brasileira, publicado no Decreto n. 9.235 (BRASIL, 2017), que estabeleceu novos parâmetros 
para o exercício das funções de regulação, supervisão e avaliação das instituições de ensino superior e dos cursos superiores e de pós-graduação no sistema federal de ensino. As principais alterações introduzidas foram identificadas e comentadas, bem como foram analisados aspectos específicos relacionados à regulação, supervisão e avaliação.

A ênfase nos resultados, característica da regulação pós-burocrática, está presente, por exemplo, com a utilização dos indicadores como instrumentos para a obtenção de autonomia. Verifica-se também a adoção de mecanismos para simplificação de processos e flexibilização das normas, como é o caso do credenciamento prévio de IES e campus fora de sede e o credenciamento de IES para a oferta exclusiva de educação a distância.

A flexibilização e simplificação de procedimentos, além da concessão de maior autonomia ao setor regulado, resultam, segundo Barroso (2005), da busca de equilíbrio e coerência de um sistema educativo cada vez mais complexo, conferindo à regulação da educação uma complexidade crescente. Bettencourt também contribui para a compreensão desse contexto ao afirmar que "[...] a regulação não assegura nem a harmonia, nem a estabilização rigorosa, nem a otimização, porque a elaboração e a aplicação das regras é uma disputa social e dá lugar a conflitos, quer abertos e violentos, quer instituídos, quer escondidos” (2004, p. 53 apud BARROSO, 2005, p. 731).

A regulamentação do Decreto n. 9.235 (BRASIL, 2017) está pendente por causa de remissões a normas complementares posteriores dos atos autorizativos, supervisão e avaliação, o que, de certa forma, gera grande fragmentação normativa.

No caso da avaliação, o decreto ampliou as competências do Inep, órgão responsável pela avaliação. Ao vincular os instrumentos de avaliação externa às diretrizes da Seres, no entanto, fica também formalizada a subordinação da atividade avaliativa à regulação, ampliando ao mesmo tempo as competências da regulação.

Deve ser ressaltada, ainda, a participação de organismos extragovernamentais na regulação da educação superior que, por meio de resoluções emitidas pelos conselhos profissionais, abordam temas relativos ao exercício profissional com reflexos sobre a formação. Esse é o caso, por exemplo, da restrição à inscrição e ao registro de egressos de cursos realizados integralmente na modalidade a distância no Conselho Federal de Odontologia e da regulação das atividades de médicos estrangeiros no Brasil e de médicos brasileiros formados no exterior pelo Conselho Federal de Medicina. A legislação vigente prevê também a manifestação do Conselho Federal da Ordem dos Advogados do Brasil (OAB) e do Conselho Nacional de Saúde (CNS) nos processos de autorização de cursos de Direito, Medicina, Odontologia, Psicologia e Enfermagem, inclusive quando ofertados por instituições dotadas de autonomia, como universidades e centros universitários. Esse tipo de participação na regulação 
remete à regulação intensiva em conhecimento e à multirregulação das políticas da educação superior, mencionado anteriormente com base em Barroso e Carvalho (2011) e Barroso (2005).

Aspecto externo à educação se associa à regulação da educação. Em 20 de setembro de 2019 foi sancionada, por medida provisória, a Lei da Liberdade Econômica, criada para desburocratizar o ambiente de negócios, estipulando, entre outros aspectos, aprovações tácitas para autorização de funcionamento caso o poder público venha a atrasar processos. Regulamentada a lei, o MEC publicou a Portaria n. 279 (BRASIL, 2020), dispondo sobre prazos para aprovação tácita e renovação de cursos e IES de responsabilidade da Seres. Essas medidas despertaram grande interesse do setor privado mercantil, ao perceber as possiblidades de ter sua aplicação na regulação da educação superior. Segundo reportagem do jornal Folha de S. Paulo, o MEC vem conversando com empresários do setor desde 2019, visando a construir um modelo para atender à demanda por desburocratização e autorregulação (SALDAÑA, 2020).

\section{REFERÊNCIAS}

AFONSO, A. J. Mudanças no Estado-avaliador: comparativismo internacional e teoria da modernização revisitada. Revista Brasileira de Educação, Rio de Janeiro, v. 18, n. 53, p. 267-490, abr./jun. 2013.

AFONSO, A. J.; MENDES, Geovana M. L. Políticas de administração e gestão em países da lusofonia: perspectivas críticas sobre a nova gestão pública e a pós-burocracia em educação. Arquivos Analiticos de Políticas Educativas, Porto, v. 26, n. 127, p. 1-6, out. 2018. Disponível em: http://dx.doi.org/10.14507/epaa.26.4254. Acesso em: 14 abr. 2020.

BARREYRO, G. B.; ROTHEN, J. C. Para uma história da avaliação da educação superior brasileira: análise dos documentos do Paru, CNRES, Geres e Paiub. Avaliação: Revista da Avaliação da Educação Superior, Campinas, SP, v. 13, n. 1, p. 131-152, mar. 2008. Disponível em: http://www.scielo.br/pdf/aval/v13n1/a08v13n1.pdf. Acesso em: 10 abr. 2020.

BARROSO, J. O estado, a educação e a regulação das políticas públicas. Educação \& Sociedade, Campinas, SP, v. 26, n. 92, p. 725-751, out. 2005.

BARROSO, J. O Estado e a educação: a regulação transnacional, a regulação nacional e a regulação local. In: BARROSO, J. (org.). A regulação das políticas públicas de educação: espaços, dinâmicas e actores. Lisboa: Educa e Unidade de I\&D em Ciências da Educação, 2006. p. 41-67. Disponível em: http://hdl.handle.net/10451/5761. Acesso em: 1 out. 2020.

BARROSO, J.; CARVALHO, L. M. Apontamentos sobre os "novos modos de regulação" à luz de estudos sobre as relações entre conhecimento e política. Propuesta Educativa, n. 36, p. 9-24, 2011.

BELLONI, I. A função social da avaliação institucional. In: DIAS SOBRINHO, J.; RISTOFF, D. I. (org.). Universidade desconstruída: avaliação institucional e resistência. Florianópolis: Insular, 2000. p. 37-58. 
BETTENCOURT, M. B. L'evaluation des établissements d'enseignement em tant que mode de régulation. Une étude de cas en enseignement collégial. 2004. 302f. Tese (Doutorado) - Faculté des Études Supérieurs, Université de Montréal, 2004.

BRASIL. Ministério da Educação. Uma nova política para a educação superior Comissão Nacional para Reformulação da Educação Superior: relatório final. Brasília, DF: MEC/SESu, nov. 1985. 134 p. Disponível em: http://www.dominiopublico.gov.br/download/texto/me002284.pdf. Acesso em: 17 set. 2020.

BRASIL. Ministério da Educação. Relatório Grupo Executivo para Reformulação da Educação Superior. Brasília, DF, set. 1986.37 p. Disponível em: http://www.schwartzman.org.br/simon/pdf/ geres.pdf. Acesso em: 17 set. 2020.

BRASIL. Ministério da Educação e Desporto. Programa de Avaliação Institucional das Universidades Brasileiras: Paiub. Brasília, DF: MEC/SESu, 1994. 111 p. Disponível em: http://www.dominiopublico.gov.br/download/texto/me002072.pdf. Acesso em: 12 nov. 2020.

BRASIL. Lei n. 9.131, de 24 de novembro de 1995. Altera dispositivos da Lei n. 4.024, de 20 de dezembro de 1961 e dá outras providências. Diário Oficial da União: Seção 1, Brasília, DF, p. 19257, 25 nov. 1995. Disponível em: https://www.planalto.gov.br/ccivil_03/leis/19131.htm. Acesso em: 12 nov. 2020.

BRASIL. Lei n. 9.394, de 20 de dezembro de 1996. Estabelece as diretrizes e bases da educação nacional. Diário Oficial da União: Seção 1, Brasília, DF, p. 27833, 23 dez. 1996. Disponível em: http://www.planalto.gov.br/ccivil_03/leis/19394.htm. Acesso em: 12 nov. 2020.

BRASIL. Decreto n. 3.860, de 9 de julho de 2001. Dispõe sobre a organização do ensino superior, a avaliação de cursos e instituições, e dá outras providências. Diário Oficial da União: Seção 1, Brasília, DF, p. 2, 10 jul. 2001a. Disponível em: http://www.planalto.gov.br/ccivil_03/decreto/2001/ d3860.htm. Acesso em: 20 fev. 2021.

BRASIL. Lei n. 10.172, de 09 de janeiro de 2001. Aprova o Plano Nacional de Educação e dá outras providências. Diário Oficial da União: Seção 1, Brasília, DF, p. 1, 10 jan. 2001b. Disponível em: http://www.planalto.gov.br/ccivil_03/leis/leis_2001/110172.htm. Acesso em: 12 nov. 2020.

BRASIL. Lei n. 10.861, de 14 de abril de 2004. Institui o Sistema Nacional de Avaliação da Educação Superior. Diário Oficial da União: Seção 1, Brasília, DF, p. 3, 15 abr. 2004. Disponível em: http:// www.planalto.gov.br/ccivil_03/_ato2004-2006/2004/lei/110.861.htm. Acesso em: 15 abr. 2020.

BRASIL. Decreto n. 5.773, de 9 de maio de 2006. Dispõe sobre o exercício das funções de regulação, supervisão e avaliação de instituições de educação superior e cursos superiores de graduação e sequenciais no sistema federal de ensino. Diário Oficial da União: Seção 1, Brasília, DF, p. 6, 10 maio 2006. Disponível em: http://portal.mec.gov.br/seed/arquivos/pdf/legislacao/decreton57731. pdf. Acesso em: 15 jun. 2020.

BRASIL. Ministério da Educação. Portaria Normativa n. 40, de 12 de dezembro de 2007 republicada em 29 de dezembro de 2010. Institui o e-MEC, sistema eletrônico de fluxo de trabalho e gerenciamento de informações relativas aos processos de regulação, avaliação e supervisão da educação superior no sistema federal de educação, e o Cadastro e-MEC de Instituições e Cursos Superiores e consolida disposições sobre indicadores de qualidade, banco de avaliadores (Basis) e o Exame Nacional de Desempenho de Estudantes (Enade) e outras disposições. Diário Oficial da União: Seção 1, Brasília, DF, p. 39-43, 13 dez. 2010. Disponível em: https://download.inep.gov.br/educacao_ superior/censo_superior/legislacao/2007/portaria_40_12122007.pdf. Acesso em: 20 fev. 2021. 
BRASIL. Decreto n. 7.480, de 16 de maio de 2011. Aprova a Estrutura Regimental e o Quadro Demonstrativo dos Cargos em Comissão do Grupo Direção e Assessoramento Superiores - DAS e das Funções Gratificadas do Ministério da Educação e dispõe sobre remanejamento de cargos em comissão. Diário Oficial da União: Seção 1, Brasília, DF, p. 1, 17 maio 2011. Disponível em: https:// www.planalto.gov.br/ccivil_03/_ato2011-2014/2011/decreto/d7480.htm. Acesso em: 12 nov. 2020.

BRASIL. Lei n. 13.005, de 25 de junho de 2014. Aprova o Plano Nacional de Educação e dá outras providências. Diário Oficial da União: Seção 1, Brasília, DF, p. 1, 26 jun. 2014. Disponível em: https://www2.camara.leg.br/legin/fed/lei/2014/lei-13005-25-junho-2014-778970-publicacaooriginal144468-pl.html. Acesso em: 12 nov. 2020.

BRASIL. Portaria Normativa n. 8, de 28 de abril de 2016. Cria indicadores de qualidade para a Educação Superior e institui Grupo de Trabalho para elaboração e definição de metodologia para sua implementação. Diário Oficial da União: Seção 1, Brasília, DF, p. 11-12, 29 abr. 2016. Disponível em: https://www.in.gov.br/web/dou/-/portaria-normativa-n-8-de-28-de-abril-de-2016-21512174. Acesso em: 15 jun. 2020.

BRASIL. Decreto n. 9.235, de 15 de dezembro de 2017. Dispõe sobre o exercício das funções de regulação, supervisão e avaliação das instituições de educação superior e dos cursos superiores de graduação e de pós-graduação no sistema federal de ensino. Diário Oficial da União: Seção 1, Brasília, DF, p. 2, 18 dez. 2017a. Disponível em: http://www.planalto.gov.br/ccivil_03/_ato20152018/2017/decreto/D9235.htm. Acesso em: 14 abr. 2020.

BRASIL. Conselho Nacional de Educação. Resolução CES/CNE n. 1, de 22 de maio de 2017. Dispõe sobre os cursos sequenciais. Diário Oficial da União: Seção 1, Brasília, DF, p. 18, 24 maio 2017b. Disponível em: http://portal.mec.gov.br/secretaria-de-regulacao-e-supervisao-da-educacaosuperior-seres/30000-uncategorised/49241-resolucoes-cne-ces-2017. Acesso em: 12 nov. 2020.

BRASIL. Ministério da Educação. Portaria Normativa n. 20 de 21 de dezembro de 2017. Dispõe sobre os procedimentos e o padrão decisório dos processos de credenciamento, recredenciamento, autorização, reconhecimento e renovação de reconhecimento de cursos superior, bem como seus aditamentos, nas modalidades presencial e a distância, das instituições de educação superior do sistema federal de ensino. Diário Oficial da União: Seção 1, Brasília, DF, p. 40-43, 3 set. 2018. Disponível em: https://www.in.gov.br/materia/-/asset_publisher/ Kujrw0TZC2Mb/content/id/39380053/do1-2018-09-03-portaria-normativa-n-20-de-21-de-dezembrode-2017--39379833. Acesso em: 15 de jun. 2020.

BRASIL. Conselho Nacional de Educação. Resolução CNE/CES n. 1/2019. Diário Oficial da União: Seção 1, Brasília, DF, p. 58, 25 mar. 2019a. Disponível em: http://portal.mec.gov.br/docman/marco2019-pdf/109901-rces001-19/file. Acesso em: 20 fev. 2021.

BRASIL. Conselho Nacional de Educação. Parecer CNE/CES n. 398, de 9 de maio de 2019. Regulamentação do $\S 2^{\circ}$ do art. 54 da Lei de Diretrizes e Base da Educação Nacional (Lei n. 9.394/1996) para permitir que instituições que não possuam o status de universidades venham a ter as prerrogativas equivalentes a elas, por alta qualidade acadêmica. 2019b. Disponível em: http://portal.mec.gov.br/docman/junho-2019/116431-pces398-19/file. Acesso em: 25 set. 2020.

BRASIL. Ministério da Educação. Portaria n. 279, de 29 de setembro de 2020. Dispõe sobre prazos para fins de aprovação tácita dos atos públicos de liberação, de responsabilidade da Secretaria de Regulação e Supervisão da Educação Superior - Seres, conforme o disposto no caput do art. 10 do Decreto n. 10.178, de 18 de dezembro de 2019. Diário Oficial da União: Seção 1, Brasília, DF, p. 227, 
30 set. 2020. Disponível em: https://www.in.gov.br/web/dou/-/portaria-n-279-de-29-de-setembrode-2020-280239080. Acesso em: 20 fev. 2021.

COMISSÃO NACIONAL DE AVALIAÇÃO. Documento Básico. Avaliação das Universidades Brasileiras, uma proposta nacional. Brasília, DF, nov. 1993. Disponível em: http://www.lite. fe.unicamp.br/grupos/formac/provao/paiub.htm. Acesso em: 17 set. 2020.

NEAVE, G. The evaluative state reconsidered. European Journal of Education, Oxford, v. 33, n. 3, p. 265-284, 1998.

NEWMAN, J.; CLARKE, J. Gerencialismo. Educação e Realidade, Porto Alegre, v. 37, n. 2, p. 353-381, maio/ago. 2012.

PEREIRA, C. A.; ARAÚJO, J. F. E.; MACHADO-TAYLOR, M. L. Remendo novo em roupa velha? Sinaes de maturidade ou de saturação do modelo de avaliação do ensino superior brasileiro. Revista Brasileira de Educação, Rio de Janeiro, v. 25, p. 1-28, 2020. Disponível em: https://www. scielo.br/j/rbedu/a/vJP4tHY38C667kdNGPbFj6S/?lang=pt. Acesso em: 20 fev. 2021.

SALDAÑA, P. Lei da liberdade econômica cria brecha para aprovar curso superior sem análise do MEC. Folha de S. Paulo, São Paulo, 1 dez. 2020. p. B5.

SOUZA, C. Z. V. A emergência das politicas de avaliação no processo de reforma da universidade brasileira. 2012. 161 f. Tese (Doutorado em Educação) - Faculdade de Educação, Universidade do Estado do Rio de Janeiro, Rio de Janeiro, 2012. Disponível em: https://www.bdtd.uerj.br:8443/ handle/1/14746. Acesso em: 14 out. 2020.

VERGER, A.; NORMAND, R. Nueva gestión pública y educación: elementos teóricos y conceptuales para el estudio de un modelo de reforma educativa global. Educação \& Sociedade, Campinas, SP, v. 36, n. 132, p. 599-622, jul./set. 2015.

ZANOTTO, M. Políticas públicas de avaliação para a educação superior no Brasil: autonomia e produção do conhecimento. 2014. 159 f. Tese (Doutorado em Educação) - Faculdade de Educação, Universidade do Estado do Rio de Janeiro, Rio de Janeiro, 2014. Disponível em: https://bdtd.ibict. br/vufind/Record/UERJ_7185cf9e00a0c6e5c4eaaacf18af9133. Acesso em: 14 out. 2020.

\section{COMO CITAR ESTE ARTIGO}

PEIXOTO, Maria do Carmo de Lacerda; PINTO, Jane Cristina da Silva. Marco regulatório da educação superior brasileira. Estudos em Avaliação Educacional, São Paulo, v. 32, e08486, 2021. DOI: https://doi.org/10.18222/eae.v32.8486

Recebido em: 22 MARÇO 2021

Aprovado para publicação em: 15 SETEMBRO 2021

Este é um artigo de acesso aberto distribuído nos termos da licença Creative Commons do tipo BY-NC. 